\title{
CARTAS DA SELVA: ALGUMAS IMPRESSÕES DE EUCLIDES DA CUNHA ACERCA DA AMAZÔNIA*
}

\section{Letters from the jungle: some of Euclides da Cunha's impressions on the Amazon}

Fabrício Leonardo Ribeiro

\begin{abstract}
RESUMO
Entre dezembro de 1904 e dezembro de 1905, Euclides da Cunha esteve na Amazônia, fazendo o reconhecimento hidrográfico das cabeceiras do rio Purus, por causa de problemas de fronteira envolvendo brasileiros e peruanos na região. Dessa viagem, o escritor deixou registradas variadas impressões acerca da vegetação, do clima, dos habitantes locais e das cidades por onde passou. Tais impressões estão presentes em volumosa correspondência e em inúmeros artigos e ensaios. A partir das cartas enviadas por Euclides antes e durante a viagem, nosso objetivo é identificar e analisar as impressões que o autor de Os sertões teve da Amazônia.
\end{abstract}

Palavras-chave: Euclides da Cunha; Amazônia; impressões de viagem.

\begin{abstract}
Between December 1904 and December 1905, Euclides da Cunha was in the Amazon, charting the course and measuring the width of the Purus river, because of frontier problems between brasilians and peruvians in that region. From that journey the writer has left recorded a variety of impressions about the vegetation, weather, peoples and cities where he passed through. Those impressions are presented in a huge amount of correspondence and in many articles and essays. Our aim is to identify and analyse these impressions of the Amazon, both before and after this trip, from the author of Os sertões.
\end{abstract}

Key-words: Euclides da Cunha; Amazon; impressions from trip.

* Mestrando em História - Unesp-Franca. Pesquisa financiada pela Capes. 
Em 30 de dezembro de 1904, Euclides da Cunha desembarcava em Manaus. O escritor havia tomado assento no vapor Alagoas no dia 13 do mesmo mês, partindo do Rio de Janeiro e passando por Vitória, Salvador, Recife, São Luís do Maranhão e Belém, rumo ao Amazonas.

Euclides fora nomeado pelo barão do Rio Branco para fazer o levantamento cartográfico das cabeceiras do rio Purus, local de conflitos envolvendo caucheiros peruanos e seringueiros brasileiros. O reconhecimento hidrográfico permitiria ao barão, ministro das relações exteriores, resolver as pendências de fronteira com o país vizinho, no que obteve êxito em 1909. Euclides da Cunha, juntamente com outras figuras letradas ilustres, freqüentava o círculo literário do barão e, como aponta Nicolau Sevcenko, após o desencantamento com a república, o autor de Os sertões inclinou-se na direção dos "grandes homens", dotados de energia e capacidade intelectual para conduzir a nação. ${ }^{1} \mathrm{O}$ barão do Rio Branco, para Euclides, tinha esses requisitos, fator que contribuiu para a aproximação dos dois.

Viajar para lugares remotos não era fato inédito para o autor de $O s$ sertões, que havia estado em Canudos entre abril e outubro de 1897, cobrindo a guerra para o jornal O Estado de S. Paulo. As impressões da viagem à Amazônia estão registradas em diversos artigos e em volumosa correspondência. Roberto Ventura destaca que, ao longo da viagem ao Purus, o escritor foi motivo de risos entre os demais membros da comissão, pois anotava tudo que acontecia de modo incessante. Dedicava-se não somente aos documentos oficiais da expedição, como relatórios, telegramas e memorandos, mas também às suas correspondências pessoais, remetidas aos familiares e amigos. ${ }^{2}$

A proposta deste artigo é observar, utilizando as correspondências de Euclides da Cunha enviadas a confrades e familiares antes e durante a viagem realizada entre dezembro de 1904 e dezembro de 1905, as impressões acerca do clima, da vegetação e dos habitantes, entre outras características da Amazônia. Para tanto, foram analisadas 70 cartas.

1 SEVCENKO, Nicolau. Literatura como missão: tensões sociais e criação cultural na Primeira República. 2. ed. São Paulo: Companhia das Letras, 2003. p. 47, 187-188.

2 VENTURA, Roberto. Euclides da Cunha: esboço biográfico. CARVALHO, Mário Cesar \& SANTANA, José Carlos Barreto (orgs ). São Paulo: Companhia das Letras, 2000. p. 241. 
A edição mais completa da correspondência euclidiana, utilizada como fonte para esse artigo, foi organizada por Walnice Nogueira Galvão e Oswaldo Galotti. ${ }^{3}$ Fruto de ampla pesquisa, a edição reúne 398 cartas distribuídas em ordem cronológica (1890-1909), e conta com um elenco dos destinatários. É válido ressaltar que se trata da correspondência ativa de Euclides da Cunha, não constando no volume as cartas recebidas pelo escritor.

A análise de cartas por parte do historiador permite que este obtenha informações não perceptíveis em outros documentos, contribuindo também para esclarecer informações já conhecidas. O estudo das cartas permite transitar em territórios íntimos, seja do amor, da amizade e/ou do conflito, bem como registrar climas de opinião, cenários de época e sociabilidades. A literatura epistolar encontra-se assim entre o documento e a ficção, a história e a literatura. ${ }^{4}$

Contudo, o historiador deve tomar cuidado com o "feitiço" dos arquivos pessoais, como alerta Angela de Castro Gomes. Corre-se o risco de tomar o conteúdo de uma correspondência como "mais verdadeiro" por ser produzido com a marca da personalidade daquele que a escreveu. ${ }^{5} \mathrm{Ou}$ tro cuidado que procuramos ter nesta análise das cartas euclidianas foi o de compreender que as impressões nelas contidas são imediatas, escritas no calor da hora, o que, no entanto, não nos permite compreendê-las como "mais autênticas" apenas por terem sido escritas durante a viagem.

Outros pesquisadores já se ocuparam das correspondências euclidianas, com temas e recortes variados. Walnice Galvão analisou as cartas que Euclides da Cunha escreveu durante o ano de 1897, período em que esteve em Canudos fazendo a cobertura jornalística do conflito. Aponta que o volume de cartas guardadas pelos destinatários intensificou-se após 1902, graças ao sucesso da publicação de Os sertões, que elevou o status de seu autor, fato que contribuiu para que hoje tenhamos acesso a esse rico

3 GALVÃO, Walnice Nogueira; GALOTTI, Oswaldo. Correspondência de Euclides da Cunha. São Paulo: Edusp, 1997.

4 GALVÃO, Walnice Nogueira; GOTLIB, Nádia Battella. Prezado senhor, prezada senhora: estudos sobre cartas. São Paulo: Companhia das Letras, 2003.

5 GOMES, Angela de Castro. Nas malhas do feitiço: o historiador e os encantos dos arquivos privados. Estudos Históricos - Dossiê Arquivos Pessoais, Rio de Janeiro, n. 21, p. 121-127, 1998. 
material. ${ }^{6}$ A relação entre Euclides e seus filhos foi analisada por Francisco Foot Hardman a partir das missivas trocadas entre eles. Foot Hardman acentua o afeto e a preocupação de Euclides da Cunha com seus filhos, demonstrados em cartas marcadas pela saudade, por conselhos e repreensões. ${ }^{7}$ Podemos destacar também o estudo de Ricardo Oliveira, que, preocupado em demonstrar Euclides como fundador de uma brasilidade sertaneja, cita algumas das cartas do autor para mostrar a marca e a presença do sertão em seu pensamento. ${ }^{8}$ Vamos então às cartas da selva.

Em carta endereçada a José Veríssimo, em junho de 1904, Euclides da Cunha revela sua intenção e desejo de viajar para a Amazônia, comentando que tal empreitada significaria "um meio admirável de ampliar a vida, o de torná-la útil e talvez brilhantíssima”. Afirma até que poderia seguir só, como fez Alexandre Rodrigues Ferreira no século XVIII, e que poderia relatar as características físicas e as riquezas da região. ${ }^{9}$ Não tardou muito e Euclides foi nomeado, em agosto do mesmo ano, chefe da comissão brasileira de Reconhecimento do Alto Purus. Entretanto, partiu para a Amazônia somente em dezembro, por causa da demora na nomeação dos demais membros da comissão, formalidades que deixavam o escritor ansioso e impaciente, como podemos observar:

... e ainda estou sem saber qual a data provável da partida porque ele nada resolveu, além da consulta que fez ao ministro, relativamente aos detalhes para se organizar a Comissão. Tudo depende da resposta àquela consulta; e eu venho pedir-lhe que influa para que ela não se demore, de modo a não se afastar muito o dia da viagem. Ainda que tenha de demorar-me em Manaus, serei mais útil lá (onde poderei firmar os preliminares dos trabalhos), do que aqui, numa atitude meramente expectante. ... ${ }^{10}$

6 GALVÃO, Walnice Nogueira. Euclides: cartas do ano da guerra. In: HARDMAN, Francisco Foot (Org.). Morte e progresso: cultura brasileira como apagamento de rastros. São Paulo: Unesp, 1998. p. 97-109.

7 HARDMAN, Francisco Foot. Pai, filho: caligrafias do afeto. Revista USP - Dossiê Nova História, São Paulo, n. 23, p. 93-101, set. 1994.

8 OLIVEIRA, Ricardo. Euclides da Cunha, Os sertões e a invenção de um Brasil profundo. Revista Brasileira de História, São Paulo, v. 22, n. 44, p. 511-537, 2002.

9 Carta a José Veríssimo, Guarujá, 24/06/1904. In: GALVÃO, W.; GALOTTI, O., op. cit., p. 207-208. A primeira referência de Euclides da Cunha sobre seu interesse em realizar uma viagem à Amazônia, presente em suas missivas, encontra-se em carta remetida a Luis Cruls, de 20 de fevereiro de 1903, p. 149.

10 Carta a Domício da Gama, 28/09/1904, Rio de Janeiro. Ibid., p. 210-211. 
Essa expectativa está presente em diversas cartas e pode ser facilmente compreendida, pois a viagem à Amazônia, de acordo com o autor de Os sertões, era de fundamental importância para o brasileiro, o engenheiro e o escritor Euclides da Cunha:

Acabo de receber do dr. Oliveira Lima um telegrama noticiando a minha próxima nomeação para a comissão de engenheiros para os limites do Peru. Não sei ainda em que cargo. De qualquer modo devo aceitar. Só terei a lucrar - como brasileiro que vai prestar um serviço à sua terra, como engenheiro que não pode ter um trabalho mais digno, e como escritor que não poderá ter melhor assunto ...11

Nem o perigo de contrair doenças tropicais como a malária e o beribéri o afastavam de seu desejo e empenho de conhecer a região amazônica. ${ }^{12}$ No período em que ficou esperando a resolução dos empecilhos que atrasavam a partida, Euclides se preparava para a "romaria de 1.500 léguas" lendo relatos e monografias de viajantes que lá estiveram, como Humboldt, Chandless, Tavares Bastos, Spix, Martius, entre outros. Consultou também relatórios administrativos e mapas das expedições anteriores. ${ }^{13}$

O seu objetivo com essa viagem não era apenas o de conhecer os cantos remotos do país, mas também o de coletar dados para um novo livro, que teria por título Um paraíso perdido, na intenção de produzir para a Amazônia obra do mesmo peso e significado que Os sertões para o sertão nordestino:

... Nada te direi da terra e da gente. Depois, aí, e num livro: Um paraíso perdido, onde procurarei vingar a Hiloe maravilhosa de todas as brutalidades das gentes adoidadas que a maculam desde o século XVIII. Que tarefa e que ideal! Decididamente nasci para Jeremias destes tempos. Faltam-me apenas umas longas barbas brancas, emaranhadas e trágicas. ... ${ }^{14}$

265-266.

11 Carta ao pai, Guarujá, 08/08/1904. Ibid., p. 219.

12 Carta a Plínio Barreto, Rio de Janeiro, 22/10/1904. Ibid., p. 240-241.

13 VENTURA, Roberto, op. cit.

14 Carta a Coelho Neto, Manaus, 10/03/1905. In: GALVÃO, W.; GALOTTI, O., op. cit., p. 
Um paraíso perdido seria, segundo Arthur Cézar Ferreira Reis, o resultado de reflexões amadurecidas e refeitas do impacto que a vegetação e o clima amazônico causaram a Euclides imediatamente à sua chegada. Seria sua interpretação da Amazônia, na qual revelaria aos brasileiros um mundo novo, desconhecido, em que o homem poderia projetar uma civilização futura. O título remeteria à visão que os viajantes tinham da América na época dos descobrimentos, como um lugar onde o homem e a paisagem estariam em sua forma primária e paradisíaca. ${ }^{15}$

A experiência nas fronteiras do país contribuiu também para a visão do escritor acerca da América Latina. Os problemas de limites territoriais e os conflitos envolvendo brasileiros e peruanos, segundo Euclides, revelavam a fragilidade do continente e a necessidade de um projeto integrador para o Brasil e os países vizinhos. ${ }^{16}$

Em Manaus, ficou instalado na casa do amigo Alberto Rangel que mais tarde escreveria Inferno verde, livro de contos sobre a região, que contou com o preâmbulo escrito por Euclides. Acreditava ficar na cidade por pouco tempo, até seguir para as cabeceiras do rio Purus. Contudo, mais atrasos sucederam, dessa vez por causa de problemas com o transporte da comissão peruana que trabalharia em conjunto com a comissão brasileira. ${ }^{17}$

Ao analisarmos as cartas escritas nesse período em que esteve em Manaus, podemos notar algumas de suas impressões acerca da cidade, do clima e dos habitantes. Além do enjôo causado pela viagem, o escritor não se adaptou facilmente ao clima quente e à umidade do local, tendo adoecido, como ilustra o trecho:

Somente hoje posso mandar-te uma breve notícia - tais as atrapalhações, tais os embaraços que nos saltearam aqui, nesta ruidosa, ampla, mal-arranjada, monstruosa e opulenta capital dos seringueiros. Eu escrevo-te doente. Conseqüências do glorious clime de não sei se ilustre ou se ingênuo Bates. Este delicioso clima traduz-se num permanente banho de vapor - e

15 REIS, Arthur Cézar Ferreira. Euclides e o paraíso perdido. In: ROCHA, Hildon (Coord.). Um paraíso perdido: reunião dos ensaios amazônicos. Petrópolis: Vozes/ INL, 1976.

16 BAGGIO, Kátia Gerab. A América Latina e os Estados Unidos na visão de Euclides da Cunha. Estudos de História, Franca, v. 7, n. 2, p. 55-68, 2000.

17 Carta ao pai, Manaus, 30/12/1904. In: GALVÃO, W.; GALOTTI, O., op. cit., p. 249-250. 
quem o suporta precisa ter nos músculos a elástica firmeza das fibras dos buritis e nas artérias o sangue frio das sucuruiúbas. Não o suporto. A febrícula de $38^{\circ}$ que me assaltou é menos um caso patológico que um incidente físico - o sangue precipitase como o mercúrio dos termômetros - e a febre aparece apenas como um reflexo da canícula.$^{18}$

Em seu “duelo com o deserto”, a Amazônia havia ganho a primeira batalha. Relembrando as observações do naturalista Henry Walter Bates viajante que veio ao Brasil em 1848, acompanhado de Alfred Russel Wallace e ficou até 1859 - acerca do clima da região, Euclides da Cunha discordou do termo glorious clime, empregado pelo naturalista, tratando-o de forma irônica (seria Bates “ilustre" ou "ingênuo" ao falar do clima local?) pois, para o escritor, a alta temperatura em que se encontrava nada tinha de gloriosa. Vale citar que, em sua obra maior, Euclides da Cunha pautou sua análise do clima local nas observações do naturalista britânico, considerando que a vida no Pará “se equilibra numa constante imperturbável”, mas, no Alto Amazonas, o escritor - sem conhecer o local ainda - identifica um "novo hábitat", que "impõe aclimação penosa a todos os filhos dos próprios territórios limítrofes”. ${ }^{19}$

Podemos notar também que Euclides, ao falar do clima, acaba exaltando a fibra do sertanejo amazônico, capaz de suportar o calor. Nessa mesma carta a Afonso Arinos, o escritor continua a elogiar os habitantes da cidade:

... Felizmente a gente é boa. Em que pese ao cosmopolitismo excessivo desta Manaus - onde em cada esquina range um português, rosna um inglês ou canta um italiano - a nossa gente ainda os domina com as suas formosas qualidades de coração e a mais consoladora surpresa do sulista está no perceber que este nosso Brasil é verdadeiramente grande porque ainda chega até cá ... ${ }^{20}$

18 Carta a Afonso Arinos, Manaus, 12/01/1905. Ibid., p. 250-251.

19 CUNHA, Euclides. Os sertões: campanha de Canudos. 39. ed. Livraria Francisco Alves Editora; Publifolha, 2000. p. 69. (Grandes nomes do pensamento brasileiro).

20 Carta a Afonso Arinos, Manaus, 12/01/1905. Ibid., p. 250-251. 
Euclides da Cunha admirou o sertanejo, sujeito oriundo da mistura do índio tapuio (destribalizado) com o migrante refugiado da seca que assolou o nordeste no final do século XIX. Victor Leonardi aponta que a impossibilidade de reproduzir o seu modus vivendi tal qual era no sertão nordestino fizera com que os migrantes abandonassem, adaptassem, inventassem e inovassem, fazendo surgir um novo homem - o sertanejo, ou caboclo amazônico - e um novo cotidiano, próprio da paisagem em que se encontravam. ${ }^{21}$

Sobre Manaus, o escritor não guardou as mesmas impressões que teve do habitante:

... Quis chegar, observar e voltar, mas cheguei e parei. Estaquei à entrada de meu misterioso deserto do Purus; e, para maior infelicidade, depois de caminhar algumas três milhas, caí na vulgaridade de uma grande cidade estritamente comercial de aviadores solertes, zangões vertiginosos e ingleses de sapatos brancos. Comercial e insuportável. O crescimento abrupto levantou-se de chofre fazendo que trouxesse, aqui, ali, salteadamente entre as roupagens civilizadoras, os restos das tangas esfiapadas dos tapuios. Cidade meio caipira, meio européia, onde o tejupar se achata ao lado de palácios e o cosmopolitismo exagerado põe ao lado do ianque espigado... o seringueiro achamboado, a impressão que ela nos incute é a de uma maloca transformada em Gand ...22

Manaus, no início do século XX, havia atravessado um rápido desenvolvimento urbano, com a pavimentação de ruas e a ampliação dos serviços públicos. Sua população usufruía dos costumes europeizados, como artigos supérfluos e objetos de luxo. Situada no ponto de convergência dos rios que escoavam o látex, Manaus beneficiava-se dessa riqueza e respirava os ares da modernidade. Nessa época a capital do Amazonas e Belém do Pará experimentavam o cosmopolitismo da belle époque e uma riqueza

21 LEONARDI, Victor. Os historiadores e os rios: natureza e ruína na Amazônia brasileira. Brasília: Paralelo 15/ UnB, 1999. p. 102; 144.

22 Carta a Domício da Gama, Manaus, ?/?/1905. In: GALVÃO, W.; GALOTTI, O., op. cit., p. 255-256. 
restrita a poucos. ${ }^{23}$ Euclides da Cunha, contrário aos estrangeirismos culturais e ao arrivismo que se instalavam por lá, não poupou Manaus de suas ferrenhas críticas. Entretanto, é interessante notarmos que a cidade paraense também vivia seus dias de "Paris nos trópicos", mas não foi alvo das críticas de Euclides e, pelo contrário, até agradou o escritor:

\begin{abstract}
... Passei ali horas inolvidáveis - e nunca esquecerei a surpresa que me causou aquela cidade. Nunca S. Paulo e Rio terão as suas avenidas monumentais largas de 40 metros e sombreadas de filas sucessivas de árvores enormes. Não se imagina no resto do Brasil o que é a cidade de Belém, com os seus edifícios desmesurados, as suas praças incomparáveis e com a sua gente de hábitos europeus, cavalheira e generosa. Foi a maior surpresa de toda a viagem ... ${ }^{24}$
\end{abstract}

Sobre a impressão que o escritor teve de Belém, Lourival Holanda de Barros afirma que a "surpresa” que a cidade causou a Euclides devia-se às suas leituras cientificistas, que pregavam a impossibilidade de uma nação civilizada nos trópicos. ${ }^{25}$ Entretanto, como explicar que Manaus e Belém, duas cidades que enriqueceram com as rendas provenientes da exploração da borracha, e até com algumas características parecidas, fossem vistas de maneira tão diversa pelo escritor? Sem discordar da afirmação de Barros, gostaria de acrescentar um outro item: a permanência forçada de Euclides em Manaus pode ter contribuído para a sua visão negativa da cidade, além, é claro, do cosmopolitismo excessivo. E o fato de ter encontrado e passado "horas inolvidáveis" acompanhado de Jacques Huber e Emílio Goeldi no Museu Paraense, isto é, com homens de ciência, num local de ciência, pode explicar sua visão positiva acerca de Belém.

A Amazônia, em geral, foi vista por Euclides da Cunha como um local que o homem ainda não estava preparado para compreender e para dominar. Terra onde o clima agia como adversário do homem, reduzindo-o

23 BRUNO, Ernani Silva. História do Brasil: geral e regional (v. 1 - Amazônia). 2. ed. São Paulo: Cultrix, [s.d.]. p. 115-145.

24 Carta ao pai, Manaus, 30/12/1904. In: GALVÃO, W.; GALOTTI, O., op. cit., p. 249-250.

25 BARROS, Lourival Holanda. Historiografia a tintas nada neutras. Revista USP, São Paulo, USP, n. 13, p. 44-47, mar./abr./maio 1992. 
à passividade perante a grandiosidade da paisagem. Podemos notar, a partir da leitura das correspondências euclidianas, a influência que os naturalistas e os cientificistas, estes últimos um pouco menos, exerceram sobre sua interpretação, entre os quais destacamos Thomas Henry Buckle e suas considerações acerca da interação do homem com o meio. Buckle defendia a idéia de que fatores físicos poderiam explicar os graus de desenvolvimento de uma civilização. Os europeus, afirmava o teórico, haviam subordinado a natureza ao homem; fora da Europa, o homem estava subordinado à natureza, que "inflamava a imaginação" e causava um "mal enorme”, como a distribuição desigual de riqueza e a impossibilidade de pensar racionalmente. ${ }^{26} \mathrm{O}$ seguinte trecho ilustra essa influência:

... E, sem o querer, achei o traço essencial deste portentoso hábitat. É uma terra que ainda se está preparando para o homem - para o homem que a invadiu fora de tempo, impertinentemente, em plena arrumação de um cenário maravilhoso. Hei de tentar demonstrar isto. Mostrarei, talvez, esteiando-me nos mais secos números meteorológicos, que a natureza, aqui, soberanamente brutal ainda na expansão de suas energias, é uma perigosa adversária do homem. Pelo menos em nenhum outro ponto lhe impõe mais duramente o regime animal. Neste perpétuo banho de vapor todos nós compreendemos que se possa vegetar com relativa vantagem, mas o que é inconcebível, o que é até perigoso pela soma de esforços exigidos, é a delicada vibração do espírito e a tensão superior da vontade a cavaleiro dos estimulantes egoísticos. É possível que uma maior acomodação me faça pensar de outro modo, mais tarde. Neste momento, porém - em que a pena me escorrega dos dedos inundados - não sei como traduzir o glorious clime de Bates. Não há exemplo de um adjetivo desmoralizado (felizmente em inglês!). ${ }^{27}$

E o escritor realmente mudou de opinião após aclimatar-se: 
... Corrijo um tópico da minha carta anterior. Escrevendo-a sob uma temperatura exaustiva de 30 graus, não tolhi algumas amargas considerações sobre este clima. Era uma impressão passageira. Já estou meio reconciliado com ele. Já compreendo um pouco o glorious clime de Bates, o delightful clime de Wallace e até o céu de opalas de Mornay. Desde o dia 13 que não aponto a temperatura sequer de $28^{\circ}$ ! E neste janeiro afogueado temos tido manhãs primaveris e admiráveis ... ${ }^{28}$

Leitor dos relatos escritos por Alfred Russel Wallace e Frederick Hartt acerca da região, Euclides tinha a impressão de que a Amazônia era ainda uma paisagem em formação. A Amazônia era considerada pelo escritor, provavelmente, como a região mais nova do mundo, motivo do pouco conhecimento por parte dos viajantes que por lá passaram ao longo dos séculos XVIII e XIX. ${ }^{29}$ Mais tarde, em artigos e estudos, Euclides retomou essa impressão de uma natureza em seu fazer-se, identificando-a como o último capítulo do Gênesis. E desvendar os segredos da Amazônia seria, nas suas palavras, o "fecho de toda a História Natural". ${ }^{30}$

Mas mesmo com toda essa bagagem de leituras das teorias cientificistas e dos relatos de viajantes naturalistas, a Amazônia não poderia ser apreendida em sua totalidade, graças à sua grandiosidade e à sua diversidade, como o escritor nos mostra em carta a Artur Lemos:

Se escrevesse agora esboçaria miniaturas do caos incompreensível e tumultuárias, uma mistura formidável de vastas florestas inundadas de vastos céus resplandecentes.

Entre tais extremos está, com as suas inumeráveis modalidades, um novo mundo que me era inteiramente desconhecido.

Além disso, esta Amazônia recorda a genial definição do espaço de Milton: esconde-se em si mesma. O forasteiro contempla-a sem a ver através de uma vertigem.

28 Carta a José Veríssimo, Manaus, 02/02/1905. Ibid., p. 261-262.

29 Essa explicação para a impressão de uma natureza em formação, presente no pensamento de Euclides da Cunha e relacionada às suas leituras dos relatos dos naturalistas está em SANTANA, José Carlos Barreto. Ciência e arte: Euclides da Cunha e as Ciências Naturais. São Paulo: Hucitec/Universidade de Feira de Santana, 1999. p. 175-176.

30 CUNHA, Euclides. O inferno verde (Preâmbulo ao livro de Alberto Rangel). In: ROCHA, Hildon (Coord.). Um paraíso perdido: reunião dos ensaios amazônicos. Petrópolis: Vozes/ INL, 1976. p. 288. 
Ela só lhe aparece aos poucos, vagarosamente, torturantemente. É uma grandeza que exige a penetração sutil dos microscópios e a visão apertadinha e breve dos analistas: é um infinito a ser dosado ...31

Keith Thomas pontua que, antes do final do século XVIII, o gosto do homem pela natureza mudou de forma dramática, ao atribuir à paisagem não domesticada um novo papel, fazendo surgir uma nova sensibilidade. "Quanto mais selvagem a cena, maior o seu poder de inspirar emoção", afirma o historiador britânico. Essa natureza selvagem tornava-se tanto um objeto de alto deleite estético quanto um lugar de privacidade e redenção espiritual, "moralmente benéfico". ${ }^{32}$ Simon Schama complementa as observações de Thomas ao caracterizar a paisagem como uma construção da imaginação sobre a natureza, levando em consideração que, quando uma determinada visão ou idéia de paisagem se forma num lugar concreto, as metáforas tornam-se "mais reais que seus referentes, tornam-se de fato parte do cenário", ${ }^{33}$

Em seus primeiros dias em Manaus, Euclides da Cunha escreveu a Oliveira Lima revelando um fato curioso; o texto dava conta de seu desapontamento com a Amazônia, porque esta não parecia com a Amazônia que havia imaginado ao ler os relatos de viajantes, que a haviam descrito como uma região exótica e misteriosa:

... Quanta coisa a dizer! - o desapontamento que me causou o Amazonas, menos que o Amazonas que eu trazia na imaginação; a estranha tristeza que nos causa esta terra amplíssima, maravilhosa e chata, sem um relevo onde o olhar descanse; e principalmente, o tumulto, a desordem indescritível, a grande vida à gandaia dos que a habitam... estou numa verdadeira sobrecarga de impressões todas novas, todas vivíssimas e

269.

31 Carta a Artur Lemos, Manaus, ?/?/1905. In: GALVÃO, W.; GALOTTI, O., op. cit., p. 268-

32 THOMAS, Keith. O homem e o mundo natural: mudanças de atitude em relação às plantas e os animais (1500-1800). Trad. João Roberto Martins Filho. São Paulo: Companhia das Letras, 1988. p. 307; 309.

33 SCHAMA, Simon. Paisagem e memória. Trad. Hidegard Feist. São Paulo: Companhia das Letras, 1996. p. 70. 
empolgantes. Preciso de uma situação de equilíbrio para o espírito .... ${ }^{34}$

A natureza passou a ser - principalmente por aqueles que estavam distantes dela - idealizada e até mitificada pelos homens, a partir do final do século XVIII. Os relatos de viagens, diz-nos Márcia Naxara, provocavam nos leitores a sensação de uma proximidade com essa natureza distante. As viagens pitorescas e as narrativas que as sucedem são, pois, “construídas culturalmente" e o que se procura está, pelo menos em parte, presente na mente e na imaginação daqueles que as produzem. ${ }^{35}$

Flora Sussekind esclarece-nos que a sensação de desapontamento pela qual o autor de Os sertões foi tomado, quando viu o Amazonas real pela primeira vez, não deve ser entendida apenas como resultado de suas leituras dos relatos de viagem, afirmando que a "intensidade da expectativa" e a "imagem prévia" foram decisivas. Para a autora, o olhar do escritor fora desarmado a partir do confronto entre o que queria encontrar e o que encontrou. ${ }^{36}$ É possível dessa forma compreender o "desapontamento" de Euclides da Cunha com a Amazônia quando em sua presença efetiva.

Já adaptado ao clima, o escritor se vê às voltas com os problemas da expedição: a falta de lanchas para o transporte da comissão peruana, a falta de instruções e a demora para partirem rumo ao Purus. A demora provocava impaciência, além de obrigá-lo a mudar de estratégia. Seria necessário navegar dia e noite para atingir os objetivos da expedição, pois o atraso da partida fez com que a comissão perdesse as condições ideais de navegação; e estavam em época da baixa dos rios, havendo o risco de as embarcações encalharem. ${ }^{37}$

A locomoção na região amazônica fazia-se com muita dificuldade. Obstáculos naturais, como a baixa dos rios, corredeiras, saltos e cachoeiras

34 Carta a Oliveira Lima, Manaus, 16/01/1905. Ibid., p. 254-255.

35 NAXARA, Márcia Regina Capelari. Cientificismo \& sensibilidade romântica: em busca de um sentido explicativo para o Brasil do século XIX. Brasília: UnB, 2004. p. 65-67.

36 SUSSEKIND, Flora. O Brasil não é longe daqui: o narrador, a viagem. São Paulo: Companhia das Letras, 1990. p. 32; 33.

37 Sobre o problema nos transportes da comissão ver Carta ao barão do Rio Branco, Manaus, 23/01/1905, p. 259; sobre a falta de instruções ver Carta a José Veríssimo, Manaus, 10/03/1905, p. 267-268; sobre o perigo de encalhe ver Carta ao barão do Rio Branco, Manaus, 20/03/1905, p. 275-276. In: GALVÃO, W.; GALOTTI, O., op. cit. 
impediam o dinamismo da navegação. Na tentativa de solucionar o problema, ao longo do século XIX haviam sido elaboradas propostas como a canalização dos trechos encachoeirados e a construção de estradas de ferro, entre elas a famigerada Madeira-Mamoré. ${ }^{38}$

De acordo com Euclides, a comissão chefiada por ele era formada por um "pequeno grupo cheio de desassombro e esperanças", e contava com duas lanchas, seis canoas e um batelão (barco mais largo, próprio para o transporte de cargas), que naufragou no dia 21 de maio de 1905, logo no início da viagem às cabeceiras do Purus, e que resultou - no final da expedição - numa situação de penúria, miséria, fome e doenças entre os membros da comissão. Euclides afirma que o convívio entre os oficiais brasileiros era harmônico. ${ }^{39}$ Entretanto, tece as seguintes impressões dos peruanos, ainda antes da partida:

... Aproxima-se o dia da minha partida; e, certo, eu a realizaria logo depois da chegada das instruções se não houvesse de aguardar que se aparelhem os peruanos. Não sei bem que tempo gastarão ainda. Noto que têm pouca pressa. Não se agitam. Quedam numa adorável placidez, em que se partem todas as minhas impaciências. Espanhóis ardentíssimos, álacres e ruidosos para as zarzuelas e para todas as requintadas troças desta desmandadíssima Manaus - são quíchuas, quíchuas morbidamente preguiçosos quando se trata de partir. Chego a imaginar que não os interessa a empresa ou que mal a toleram, contrariados. E como nos querem mal! ... ${ }^{40}$

De acordo com as informações fornecidas pelo biógrafo Sylvio Rabelo, as relações entre as duas comissões eram instáveis e Euclides e Dom Pedro Buenaño “apenas se toleravam”, por causa das funções que deveriam exercer em nome dos respectivos governos. Os peruanos, segundo Rabelo, divertiam-se com o excesso de zêlo e seriedade com que Euclides

38 HARDMAN, Francisco Foot. Trem-fantasma: a ferrovia Madeira-Mamoré e a modernidade na selva. 2. ed. São Paulo: Companhia das Letras, 2005. p. 143-144.

39 Sobre a composição e o convívio dos membros da comissão ver Carta a José Veríssimo, Manaus, 02/02/1905, p. 261-262; sobre o naufrágio do batelão ver Carta ao pai, Novo Lugar, 05/06/1905, p. 283. In: GALVÃO, W.; GALOTTI, O., op. cit.

40 Carta a José Veríssimo, Manaus, 19/03/1905. Ibid., p. 274-275. 
da Cunha encarava a sua tarefa, apesar das adversidades que sua comissão atravessava, ao passo que a comissão peruana gozava de boa saúde e farta alimentação. ${ }^{41}$

A freqüência das cartas escritas por Euclides da Cunha diminui a partir de abril (data em que partiu para o Purus) e regulariza-se apenas em novembro (novamente instalado em Manaus). Podemos deduzir que, por causa da navegação e do aumento do volume de trabalho da expedição, o escritor-engenheiro teve menos tempo e condições para dedicar-se às suas correspondências. Nesse ínterim, o maior destinatário foi o barão do Rio Branco e o conteúdo das cartas referia-se sempre aos trabalhos da comissão.

À medida que se afastava de Manaus e seguia rumo aos cantos mais remotos da Amazônia, a impressão que Euclides teve foi a de uma região deserta - esquecida ou abandonada:

... Entre o Chandless e aquele ponto a região é deserta, aparecendo junto às margens uma ou outra barraca abandonada. Dali até aqui, porém, muito mais povoada de brasileiros. Porto de Mamoriá, fronteira de Cassianã e Novo Triunfo são três sítios florescentes, de laboriosos e robustos cearenses que firmam bem nestes lugares o domínio da nossa terra. ... ${ }^{42}$

Em contato com uma região marcada pelo isolamento geográfico e pelo povoamento escasso, podemos perceber outra impressão positiva de Euclides sobre o sertanejo que veio do Nordeste para trabalhar na produção do látex em seringais espalhados pela selva: o papel de povoador daquelas paragens. Essa visão de abandono, presente em suas cartas e retomada nos seus estudos posteriores, foi a base de suas críticas à situação marginal da Amazônia, na qual o distanciamento não era somente geográfico, mas também cultural e social, pensamento que deu sustentação aos seus projetos para a integração da região ao conjunto da nação por meio das ferrovias, da navegação e dos telégrafos. 
O escritor-engenheiro retornou a Manaus em outubro, e lá permaneceu até dezembro, ocupado com a redação do relatório da comissão junto com Pedro Buenaño, chefe da comissão peruana.

Em tais correspondências, já podemos notar as primeiras manifestações de uma interpretação euclidiana da Amazônia. Ao nosso ver, uma interpretação nada homogênea da região, construída a partir de leituras e matrizes de pensamento díspares, que marcaram tanto o pensamento de Euclides quanto o de toda sua geração. Uma visão em dois momentos, como mostram as cartas analisadas nas páginas anteriores: no início, um certo desapontamento e juízos pessimistas sobre a Amazônia; depois, a crítica e a denúncia, tão presentes no conjunto de sua obra, vieram à tona.

Voltando à carta de agosto de 1904, endereçada ao pai, podemos concluir que a viagem foi de grande valia para o brasileiro, o engenheiro e o escritor Euclides da Cunha. Em um momento no qual o país atravessava problemas diplomáticos e o autor buscava se consolidar entre os grandes homens das letras e das ciências, uma interpretação do Brasil, integrando a Amazônia, fazia-se fundamental. 